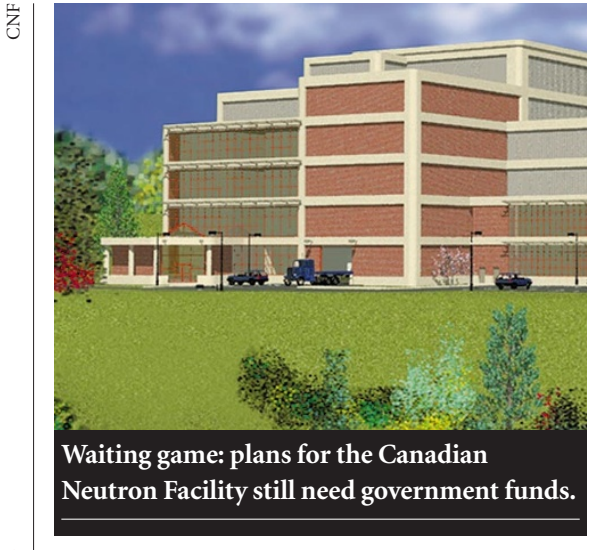

- uranium) designs for nuclear power stations have had some export success.

The double use of the facility means that its fate rests not just on the scientific case for a neutron facility, but also on the perceived importance of AECL's power reactor development programme at a time when few nuclear power stations are being built anywhere in the world.

"The dual use thing is a double-edged sword," says Thom Mason, a Canadian who is leading the project to build a $\$ 1.3$ billion neutron source at the Oak Ridge National Laboratory in the United States. "The case for neutron scattering is accepted, but the decision hinges on the future of CANDU, and that is totally decoupled from the scientific community's need for neutrons."

Mason is a strong supporter of the Canadian project. But if lack of funding causes the Canadian team to disintegrate, progress at the US facility, together with a new target chamber at ISIS in the United Kingdom and an imminent decision to build a neutron source in Australia, could all attract people away from Canada.

The $\mathbf{3 0 0}$ or so Canadian researchers who use neutrons say that failure to fund the facility will cause Canada to lose its long-standing leadership in neutron scattering, for which Canadian physicist Bertram Brockhouse won a Nobel Prize in 1994. "Neutron sources in the United States are heavily oversubscribed - we can't get beamtime there," says Buyers.

Researchers see the CNF as completing an important trio of national scientific facilities, together with Triumph, a particle accelerator in British Columbia, and the Canadian Light Source, a synchrotron light source being built at Saskatoon in the province of Saskatchewan.

But the CNF hasn't received financial support from the province of Ontario. And, ironically, the fact that the province is overwhelmingly loyal to the Liberal party of Jean Chretien, the Canadian prime minister, may actually reduce pressure on him to fund construction of the facility.

Colin Macilwain

\title{
US reforms rules for telling public about GM food
}

\section{Washington}

The Clinton administration has announced a series of regulatory changes and research proposals intended to shore up public confidence in the government's supervision of genetically modified (GM) food.

The Food and Drug Administration (FDA) will in future require companies that wish to introduce any new transgenic food to provide notice and supporting scientific research 120 days in advance. This information will then be placed on the Internet for public inspection. At present, companies submit this information on a voluntary basis, and it is not automatically made available to the public.

The FDA will also develop guidelines for the voluntary labelling of GM food, and will permit producers of food containing no GM organisms to label it as such.

But the changes, which were announced last week by the White House in conjunction with the FDA, the US Department of Agriculture (USDA) and the Environmental Protection Agency (EPA), did not include any mandatory requirement for the labelling of GM foods.

Although widely expected, this omission led most environmental groups to reject the changes, which they branded as cosmetic. Farming and industry groups, meanwhile, warmly welcomed the announcement. The National Corn Growers Association, which represents most large maize farmers, said the changes matched its own policy and position, as stated during public hearings conducted by the FDA last autumn (see Nature 402, 571;2000).

Farmers and the agricultural biotechnology industry have been pressing the government to make such changes, in the hope that they will strengthen US public confidence in GM food. GM foods are already ubiquitous in the food chain in the United States, where around half of this year's soybean crop and one-third of the maize will be transgenic.

The industry is concerned that European rejection of the technology will spill over into the United States, where GM crops were introduced after extensive scientific review but minimal public debate.

The USDA, FDA and EPA also pledged to coordinate their research programmes on the safety and risk assessment of agricultural biotechnology, although the amount of additional money to be made available for this was not specified. The USDA also said it will create standards to certify the various testing procedures that are available to establish whether foods contain GM organisms.

The White House Office of Science and Technology Policy and the Council of Environmental Quality said that they would conduct a further six-month study on the regulation of agricultural biotechnology. Under a long-standing arrangement, the FDA, EPA and USDA share responsibility for this regulation, depending on the intended function of the genetic modification.

Colin Macilwain

\section{Italian genomics boost retained}

\section{Munich}

In Italy, scientific initiatives tend to change with governments. But prime minister Giuliano Amato's new administration has retained a plan to launch strategic research programmes in human genomics and neuroscience.

Only days before the previous government fell last month, it issued a decree setting up two national committees to define the strategies. The decree was the brainchild of Vincenzo Sica, undersecretary of state for research, who has been reappointed to his position.

The committees, which met for the first time earlier this week, will put forward both scientific and financial proposals. If all goes according to Sica's plan, these will be worked into next year's research budget.
Sica hopes that substantial sums of money will start to flow early next year. "We'll need at least IL100 billion [US\$46 million] per year, and probably a lot more," he says.

Given the unpredictability of Italian politics - and the infighting at the ministry over the control of any genomics programme - this timetable may be a little optimistic. But if it works it will give Italian biology, long hampered by underfunding and poor management, a shot in the arm.

"Like all areas of biomedicine, the small amounts of funding available to neuroscience research are distributed thinly across a large number of research groups, and not strategically coordinated," says Piergiorgio Strata, professor of 
- neurophysiology at the University of Turin, who will coordinate the neurosciences committee.

Genome research has struggled to gain a toe-hold in Italy. "Italy has been the only one of the G8 countries not to have a genome project, or any serious money for genome research from the state," says Andrea Ballabio, director of the Telethon Institute of Genetics and Medicine in Milan, and a member of the genomics committee, now called the Committee for Medical Genetics.

This concern led Ballabio, along with several other top geneticists and molecular biologists in Italy, to create an informal group called the Genome Task Force. This spent more than a year working in secret to escape external pressures - on a strategy paper for genome research. It had planned to present the paper to the research ministry, when it was overtaken by Sica's initiative.

The paper suggests the creation of national centres to service fields such as genotyping, bioinformatics, expression profiling and proteomics. It also advocates the support of projects to develop animal models for genetic diseases, and to build on strengths in population genetics. This paper is likely to be a springboard for the national committee's discussions.

"The committee is an important first step for us," says Ballabio, "and it is certainly not too late for Italy to catch up — the interesting genome work is only just starting now that the sequences are being completed."

Although the genomics and neurosciences national committees will define broad strategic goals, they will not control the distribution of grant money. This will be based on the advice of a panel of international experts.

Sica, a neuropathologist from the University of Naples, was appointed undersecretary of state for research last December. Knowing that his time in office would be short - government collapses notwithstanding, general elections are due in Italy next year - he has concentrated on

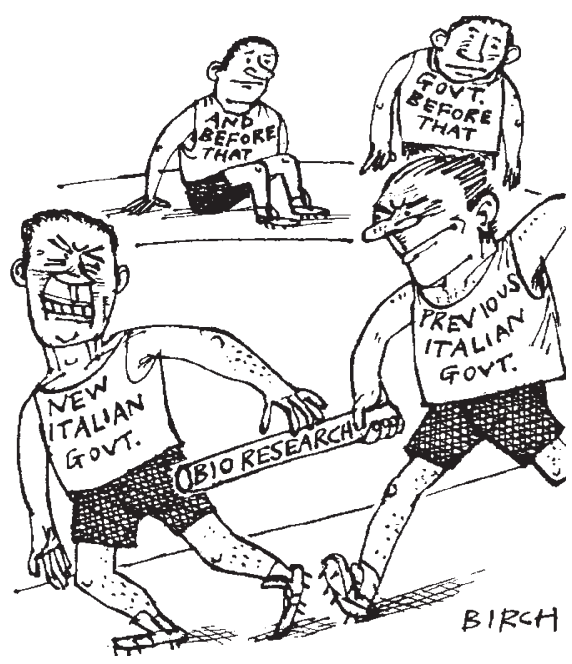

pushing through initiatives in what he believes to be the two most important research areas. Many of the scientists on the two committees feel that Sica's initiative would almost certainly have evaporated had he not been reappointed. Alison Abbott

\section{Israel debates raising commitment to CERN}

\section{Jerusalem}

Keen to boost its role in the European scientific community, Israel's science ministry is considering whether to apply for full membership of the European Laboratory for Particle Physics (CERN). But although some Israeli physicists are enthusiastic, others worry about the the financial and scientific implications.

The 1992 agreement granting Israel observer status, similar to other countries such as the United States, Japan and Russia, is about to expire. Under this agreement, Israel pays 20 per cent of full membership dues - about 2 million Swiss francs (US\$1.2 million) a year. In exchange, Israeli researchers and postdocs can participate in CERN research programmes, and Israeli companies can bid for CERN tenders.

Renewal of observer status seems the most likely short-term outcome. But some Israeli particle physicists are pushing hard for full membership. The reasons, they admit, are as much political as scientific.

"Israel is no longer a Third World country. It has to take responsibility for the things that large countries do. It has to support first-class science," says Giora Mikenberg, professor of particle physics at the Weizmann Institute of Science.

Mikenberg, who leads the muon project at CERN's Large Hadron Collider, thinks that membership of CERN could lead to Israel becoming a full partner in other European scientific programmes - such as the European Space Agency - and

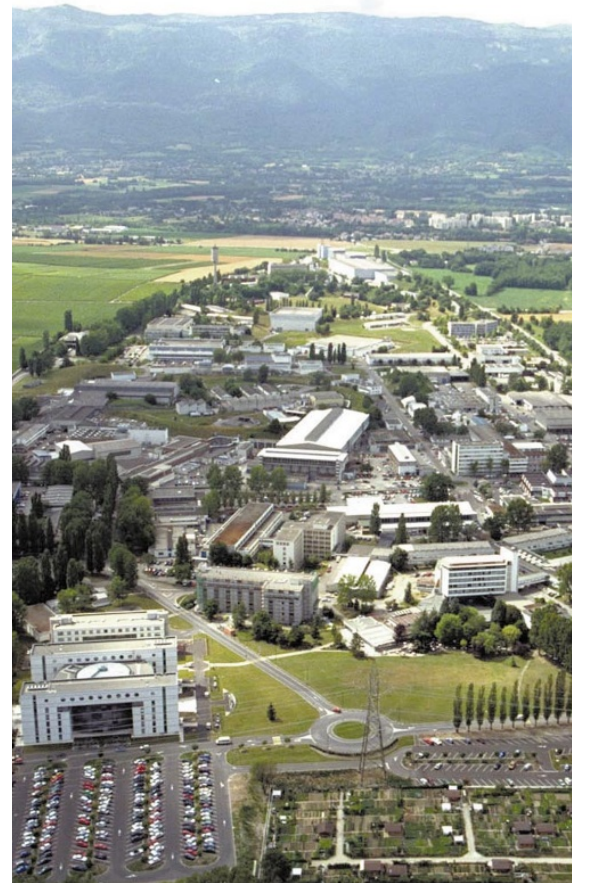

Collision course: Israeli physicists are divided over the benefits of full membership of CERN.

would show that Israel was a scientific power of the first rank. Full membership would also allow Israelis to be CERN employees and to participate in scientific decision-making there.

The main problem, Mikenberg acknowledges, is the price tag. The ministries of science and industry, which fund Israel's observer status at CERN, will not be able to finance full membership, meaning that the cabinet would have to allocate money from the national treasury, he says.

Israeli minister of science Matan Vilnai visited CERN recently and was impressed by what he saw. An informal ministry forum of industrialists, researchers and government officials has discussed full membership and made a favourable recommendation to Vilnai.

Sources in the ministry claim that Vilnai discussed the possibility of full membership with CERN officials. But CERN directorgeneral Luciano Maiani denies having any conversations about the matter with Vilnai or anyone else. "The issue is not on the agenda," he insists. "There is no official move in that direction."

Other Israeli physicists are doubtful about the scientific benefits of full membership, and worry that it might actually have negative consequences. Shmuel Nussinov, a theoretical physicist at Tel Aviv University, says that he would welcome closer ties with CERN, but worries that the additional funding needed might come at the expense of existing research.

Another physicist says that, at present, Israeli physicists can participate in CERN research projects but have other options. Full membership of CERN could mean putting all the country's eggs in one basket, he says, and might make it harder for Israelis to find funding to take part in particle-physics research elsewhere.

Haim Watzman 